\title{
Rhetoric in Song Lyrics Malam Terakhir and Satukan Hati Kami as Contribution for Character Building Through Literature Education
}

\author{
Sugeng Purwanto ${ }^{1, a)}$, Endang Yuliani Rahayu ${ }^{1 b)}$ \\ ${ }^{1}$ Universitas Stikubank (UNISBANK) Semarang \\ Jalan Trilomba Juang No. 1 Semarang, Indonesia \\ E-mail: ${ }^{\text {a) }}$ drpsugeng@yahoo.com \\ b)endangyuliani@gmail.com
}

\begin{abstract}
The current study aims to analyze the rhetoric employed in two song lyrics, namely Rhoma Irama's Malam Terakhir and Pance Pondaag's Satukan Hati Kami to identify the similarities and differences in creating the values of religiousness and romantisism in order to contribute to Indonesian Literature Education in relation to youth's character building. With the use of genre analytical framework under discourse analysis, the two song lyrics were analyzed to identify (1) communicative purposes, (2) generik structure and (3) linguistis features. Meanwhile, to investigate the value of religiousness and romantisism, a survey was administered to 20 students of Faculty of Language and Cultural Studies, Stikubank University only to find out that the two song lyrics created different discourses with different proportion of religiousness and romantisism. The findings yielded conclusion and recommendations to further expand the scope of literature teaching, especially with respect to the youth's character building.
\end{abstract}

Keywords: rhetoric, song lyrics, literary work, character building

\begin{abstract}
Abstrak
Penelitian ini bertujuan menganalisis retorika yang dipakai pada dua lirik lagu Malam Terakhir karya Rhoma Irama dan Satukan Hati Kami karya Pance Pondaag untuk mencari titik temu kedua lagu tersebut dalam menguraikan nilai-nilai religiusitas dan romantisme serta menggali kontribusinya terhadap pembentukan karakter remaja melalui pengajaran karya sastra. Dengan menggunakan kerangka analisis genre dalam bingkai analisis wacana, kedua lirik lagu tersebut dianalisis untuk mengidentifikasi (1) tujuan komunikatif, (2) struktur generik dan (3) fitur-fitur linguistis. Sedangkan untuk menggali nilai-nilai religiusitas dan romantisme, dilakukan survei terhadap 20 mahasiswa Fakultas Bahasa dan Ilmu Budaya, Universitas Stikubank Semarang sebagai subyek penelitian. Hasil penelitian ini menunjukan adanya perbedaan dalam olah wacana, dan proporsi nilai-nilai religiusitas dan romantisme kedua lagu tersebut. Hal ini
\end{abstract}


memungkinkan ditarik simpulan dan rekomendasi untuk mengembangkan pengajaran karya sastra sebagai sarana pembentukan karakter remaja.

Kata kunci: retorika, lirik lagu, pendikan sastra Indonesia

\section{PENDAHULUAN}

Lirik lagu-lagu lama sekelas karya Rhoma Irama dan Pance Pondaag masih diminati banyak orang. Akan tetapi bagi orang yang pada saat naik daunnya lagu tersebut masih remaja, hal ini akan menjadi kenangan tersendiri. Mereka saat ini ratarata sudah berusia 50 tahunan. Apabila diperdengarkan lagu-lagu tersebut, mereka serasa muda kembali dan terkenang saat-saat remaja (Falah, 2019), saat memadu cinta yang tentunya akan sangat berbeda dengan remaja masa kini dengan berbagai alat berteknologi digital. Saat itu internet belum terbayangkan. Komputer pun masih sebatas ketik mengetik dengan wordstar di era 1990-an.

Penelitian ini mengkaji lirik lagu Malam Terakhir karya Rhoma Irama (UMAM, 2016) dan Satukan Hati Kami karya Pance Pondaag (Herlin, 2015). Kedua lagu tersebut memiliki basis irama yang berbeda. Malam Terakhir termasuk kategori genre dangdut, sedangkan Satukan Hati Kami ber-genre pop. Namun demikian ada kesamaan dalam lagu-lagu tersebut, yakni dalam hal pembentukan wacana (discourse formation) 'ditinggal kekasih'. Channel Youtube membuktikan bahwa lagu-lagu semacam itu masih banyak penggemarnya dilihat dari banyaknya 'likes'. Kehebatan kedua lagu tersebut adalah bahwa masing-masing lagu mengandung nilai religiusitas berupa pesan moral di samping tentunya ada sentuhan romantisme. Lagu Malam Terakhir bersifat temporer sedangkan lagu Satukan Hati Kami bersifat kilas balik (flashback). Keduanya mengisahkan adanya salah satu pasangan yang harus meninggalkan kekasihnya untuk jangka waktu tertentu. Hal ini mengundang urgensi untuk melakukan penelitian dalam rangka mencari media pembelajaran untuk pembentukan karakter para remaja (Mintargo, Soedarsono, \& Ganap, 2014), yang apabila kita mau jujur remaja sekarang nampak sudah kehilangan jati dirinya. Hal ini dapat dilihat dengan banyaknya tawuran remaja dan berbagai tindakan negatif lainnya disamping menurunya tingkat kesopanan mereka terhadap para seniornya. Asumsi sementara mereka kurang mendapatkan sentuhan jiwa melalui karya sastra (Wardoyo, 2009; Suhita \& Purwahida, 2018).

Lirik lagu karya Rhoma Irama sudah banyak diteliti di kalangan akademisi terutama fokus pada nilai-nilai moral dan religiusitas. Nilai-nilai moral yang terdapat dalam lagu-lagu karya Rhoma Irama di Album Soneta VIII dan Soneta XIV telah diteliti, dan temuan yang diklaim adalah bahwa lagu-lagu dalam kedua Album tersebut memiliki nilai moral religi, antara lain budaya toleransi, saling menghormati, keterbukaan, rasa malu, dan cinta kasih (Sari, n.d.). Di samping itu, nilai-nilai tauhid juga pernah diteliti (Umaya, 2018) dalam lagu-lagu Rhoma Irama, dan disimpulkan bahwa setelah Rhoma Irama pulang dari menunaikan ibadah haji, dia lebih banyak mencipta lagu-lagu yang bersifat religi. Seperti diketahui bersama bahwa nama Rhoma adalah nama baru dari nama lama Oma. "Rh" adalah singkatan dari Raden Haji. Hingga sekarang sang raja ndangdut lebih terkenal dengan nama Rhoma Irama.

Pembelajaran nasionalisme juga bisa dilakukan lewat lirik lagu-lagu Rhoma Irama (Khodijah, 2018). Beberapa lagu-lagu Rhoma Irama mengandung nilai-nilai nasionalisme.Khodijah menyimpulkan adanya kesempatan para pemusik untuk 
mencipta lagu yang ada muatan nasionalisme untuk menanggulangi krisis nasionalisme Indonesia.Oleh karena itu, tidak berlebihan jika penelitian ini bermuara pada pembentukan karakter remaja melalui pengajaran sastra dengan obyek lirik lagu.

Sementara itu, penelitian lirik lagu karya Pance Pondaag belum pernah ditemukan. Bisa jadi, hal ini akibat viralnya berita di tahun 1980-1990an tentang lagulagu cengeng yang banyak disinyalir oleh Departemen Penerangan paada era Orde Baru. Penelitian ini mengangkat lirik lagu Pance Pondaag dengan asumsi adanya kesamaan pesan moral dengan lagu 'Malam Terakhir karya Rhoma Irama.Penelitian ini fokus pada analisis perbandingan rhetorika antara Rhoma Irama dan Pance Pondaag dalam mensikapi peristiwa 'perginya' kekasih.

Permasalahan yang akan dijawab melalui penelitian ini meliputi (1) tujuan komunikatif, (2) struktur generik dan (3) fitur linguistis lirik lagu Malam Terakhir dan Satukan Hati Kami dengan menggunakan Kerangka Teoritis genre analysis dalam bingkai discourse study (kajian wacana).

Berkaitan dengan genre musik di Indonesia, dalam khasanah permusikan di Indonesia dikenal adanya dua genre yang sangat menonjol di Indonesia, yaitu genre pop dan genre dangdut. Keduanya saling berebut simpati dari generasi tua maupun generasi muda. Bahkan ekstrimnya, lirik pop juga dapat digubah ulang menjadi lirik dangdut, dan begitu juga sebaliknya lirik dengan irama dangdut digubah ulang menjadi irama pop.

Tidak dapat dipungkiri bahwa untuk pemilihan genre itu bersifat pribadi dan tidak ada hubungan dengan status social. Namun demikian, ada semacam dikotomi dari segi praktisi atau penggemar bahwa dangdut itu adalah jenis music dengan yang dirancang untuk kelompok orang kelas rendah. Sementara itu, genre pop termasuk untuk penggemar pada kelas atas (Sitowati, 2010). Benarkah demikian? Survey membuktikan bahwa ada sekelompok orang yang menyukai ke dua music tersebut (Alviani, 2012). Pilihan apakah menyukai dangdut atau pop bersifat situational dan individual (pribadi)

Musik apapun genre nya pasti ada pesan moral yang hendak disampaikan. Pesan moral tersebut ada yang bersifat implisit maupun eksplisit (Islami, 2016). Dalam penelitiannya, Islami mengambil lirik lagu karya Ebiet G. Ade, antara lain Berita kepada kawan", "Untuk kita renungkan", "Masih ada waktu", "Aku ingin pulang", dan "Kepadamu Aku Pasrah" Lirik lagu-lagu tersebut dianalisis dengan model analisis diskursus Teun A Van Dijk. Hasilnya cukup mengejutkan bahwa pesan dahwah Islam dapat dilakukan melalui lagu.

Sementara itu, lirik lagu-lagu Rhoma Irama juga pernah diteliti sebagai media dakwah (Veronika, 2016). Veronika membuat analisis deskriptif untuk mencari tahu dakwah yang disampaikan Rhoma Irama melalui lirik lagu-lagunya, yang ternyata simpulanya adalah bahwa orang akan lebih mengerti nilai-nilai religi yang ditampilkan melalui karya seni, dan bukan semata-mata menggunakan metode tradisional, seperti ceramah-ceramah keagamaan.

Nilai-nilai moral yang terdapat dalam lirik lagu lagu Rhoma Irama juga pernah diteliti (Romadhon, 2013). Romadhon meneliti adanya etika para penggemar dangdut Rhoma Irama.Ternyata mereka lebih dapat belajar moral agama dan etika pergaulan setelah mendengarkan lagu Rhoma Irama. Dapat disimpulkan bahwa pendidikan moral dapat dilakukan melalui lagu-lagu religi.

Dalam penelitian ini, teori analisis genre (genre analysis) yang dipakai adalah mengacu pada teori (Askehave \& Swales, 2001). Dalam teori tersebut dikatakan bahwa sebuat teks dapat dianalisis genre-nya melalui investigasi tiga ranah, yakni (1) tujuan 
komunikatif teks tersebut, (2) struktur generik dan (3) fitur linguistis, yang digunakan untuk kontruksi teks (Bhatia, 1999). Lebih jauh lagi menyangkut lirik lagu fitur tekstualnya tentu sangat berbeda dengan teks tertulis biasa. Perbedaan ini menyangkut kepadatan (compacted) leksikal dan ciri khas sebagai lirik lagu yakni singkat padat (succinct). Dengan kata lain lirik lagu identik dengan ciri padat bentuk namun luas informasi (Kizer, 1983).

Dengan demikian, sebuah lirik lagu memiiki struktur generik yang diolah sedemikian rupa agar dapat mencapai tujuan komunikatif lirik lagu tersebut (Yunus, 2018). Adapun cara mencapai tujuan komunikatif tersebut tentunya, di samping tercermin dalam sttuktur generik, juga dapat diamati dari fitur linguistis (gramatikal) dari setiap baris lirik lagu, yang biasanya kelihatan agak menyimpang dari kaidah bahasa lisan maupun tulisan. Hal ini disebabkan lirik lagu lebih mengedepankan irama lagu, sehingga kemungkinan besar menimpang dari kaidah tatabahasa, namun tetap pada ranah komunikatif.

Dalam perspektif Systemic Functional Linguistiss (SFL), penggunaan bahasa itu ditujukan untuk mencapai tiga ranah makna sekaligus, yakni (1) makna gagasan, (2) makna antar pribadi dan (3) makna tekstual (Wiratno, 2016). Ketiga ranah tersebut dicapai melalui pendekatan leksiko-gramatika dengan mengacu pada struktur generik yang dikehendaki untuk mencapai tujuan komunikatif tertentu. Dengan kata lain, ketiga ranah makna tersebut dapat juga dijelaskan dalam tiga variable register, yakni apa (field), bagaimana diekspresikan (tenor) dan struktur yang dipakai (mode) dalam suatu wacana tertentu (Halliday, Matthiessen, \& Halliday, 2014)

Perubahan pada struktur generik, fitur linguistis akan sangat mempengaruhi ketiga makna tersebut dan tentunya akan menimbulkan dampak baik negative maupun positif terhadap tujuan komunikatif (Rokhmansyah, 2014). Dari ketiga makna seperti telah disinggung sebelumnya, yang paling rigid bertahan adalah field of the discourse (isi wacana). Sedangakan tenor of the discourse (makna hubungan antara pribadi) dan mode of the discourse (struktur tekstual wacana) sangat rentan berubah sesuai dengan tujuan dan maksud si pebahasa. Misalnya unsur sopan santun dan sikap tentunya akan banyak tercermin dalam tenor dan struktur thema-rhema akan teraktualisasi dalam mode wacana (Zolkifli, Bakar, \& Saniah, 2011).

\section{METODE PENELITIAN}

Penelitian ini menggunakan pendekatan (ancangan) eksploratif, deskriptif dan explanative (Hamdi \& Ismaryati, 2014) mengkaji lirik lagu 'Malam Terakhir' karya Rhoma Irama dan 'Satukan Hati Kami' karya Pance Pondaag, dalam hal penggunaan retorika, melalui analisis genre. Adapun satuan analisisnya berupa bait-bait lirik lagu yang akan dianalisis berbasis baris-baris dalam satu bait tertentu. Field, tenor dan mode of the discourse dapat ditentukan secara intuitif sebagai basis menentukan tujuan komunikatif lagu yang bersangkutan (Saksono, 2009). Dari tujuan komunkatif, bisa ditarik menjadi bahan kajian untuk menentukan struktur generik lirik lagu. Bagian yang lebih dalam dari struktur generik adalah fitur gramatika deangan mana unsur-unsur terkecil bahasa dapat diberikan label nama, yang lebih pada unsur fungsi.

Data yang berupa lirik lagu 'Malam Terakhir' karya Rhoma Irama diunduh dari https://lirik.kapanlagi.com/artis/rhoma-irama/malam-terakhir/ sedangkan lirik lagu sebagai obyek pebanding adalah 'Satukanlah Hati Kami' yang diunduh melalui Google 
Search

Engine

dari

https://www.wowkeren.com/lirik/lagu/pance_f_pondaag/satukanlah-hati-kami.html.

Kedua lagu tersebut akan dianalisis dengan menggunakan Genre Analytical procedures dengan bertumpu pada tiga butir permasalahan yakni: (1) Tujuan komunikatif, (2) Struktur generik dan (3)fitur linguistis dari kedua lagu tersebut. Hasil analisis ketiga butir permasalahan masing-masing lagu dibakai sebagai basis dalam menganalisis perbedaan dan kesamaan kedua lagu tersebut untuk nenakar tingkat romantisme dan religiusitas Rhoma Irama dan Pance Pondaag. Oleh karena itu untuk menginvestigasi retorika yang dipakai kedua penyanyi tersebut, tim peneliti menggunakan analisis survei terhadap 20 mahasiswa FBIB program studi sastra Inggris agar menjadi 'judge' untuk mendukung interpresasi peneliti dalam menakar religiusitas dan romantisme. Survei menggunakan skala Likert dan dianalisis secara proporsional menggunakan prosentase $(\%)$.

\section{HASIL DAN PEMBAHASAN}

Untuk mengungkap tujuan komunikatif kedua lirik lagu tersebut, penulis akan memulai deskripsi bait-bait pada masing-masing lirik lagu.

Rhoma Irama

\section{Malam ini malam terakhir bagi kita \\ Untuk mencurahkan rasa rindu di dada \\ Esok aku akan pergi lama kembali \\ Kuharapkan agar engkau sabar menanti}

Pada baris pertama seorang pria memberikan pernyataan inti untuk membentuk suatu wacana tertentu (discourse formation). Apabila seorang wanita mendengar pernyataan seperti pada baris pertama, tentunya dia akan membangun persepsi dalam pertanyaan:

1) Ada apa dengan malam ini?

2) Mengapa dikatakan sebagai malam terakhir?

3) Apa yang akan terjadi pada malam terakhir itu?

Pertanyaan nomer 3 (tiga) sudah terjawab pada baris ke dua, yaitu "Untuk mencurahkan rasa rindu di dada." Pernyataan ini juga menimbulkan pertanyaan lebih lanjut, yaitu aktifitas apa yang normalnya dilakukan oleh sepasang remaja dalam mencurahkan rasa rindu di dada. Secara dogmatis, remaja kekinian para remaja yang akan berpisah untuk waktu yang lama, mereka akan berbagi cerita, janji-janji masa depan jika kelak mereka berkumpul lagi. Merbukti, Rhoma Irama juga melukiskan dalam dua baris berikut:

\section{Semakin lama kita berpisah \\ Semakin mesra untuk berjumpa}

Dalam lagu "Malam Terakhir" ada semacam penegasan bahwa perjumpaan yang mesra itu terjadi saat pada malam perkawinan:

Kita akan berjumpa di saat bahagia

Di saat malam pesta perkawinan kita

Di sini dapat disimpulkan bahwa kemesraan menurut Rhoma Irama adalah kemesraan yang terjadi pada saat pesta perkawinan; sekaligus menolak anggapan bahwa 
pada waktu mereka menghabiskan malam terakhir, mereka melakukan hal-hal yang dilarang agama, misalnya melakukan hubungan badan layaknya suami-istri.Terjadi janji-janji dan harapan, 'semakin lama kita berpisah semakin mesra saat berjumpa' itu dapat digolongkan sebagai janji dan harapan.

Sebagai wanita, tentu memiliki rasa keraguan apakah mungkin dia dapat kembali berkumpul dengan sang kekasih, mengingat skala perselingkuhan sudah pada batas yang mengkhawatirkan, apa lagi mereka sekedar baru kekasih, dan belum menjadi suami istri. Rhoma Irama, dalam hal ini, meyakinkan bahwa dia akan kembali dan menemui kekasihnya setelah semua tugas selesai dilaksanakan seperti baris-baris lirik berikut. Namun bagi orang yang beragama, tentunya semua tergantung takdir Tuhan yang Mahakuasa:

\section{Kepergianku hanya untuk kembali \\ Kita berpisah untuk berjumpa lagi \\ Kecuali bila Tuhan menghendaki \\ Tentu saja kita harus rela hati \\ Karena kehendak-Nya itu yang terjadi}

Itulah lima baris terakhir lirik lagu yang menunjukkan nilai religiusitas yang tinggi, bahwa semua diserahkan pada kekuasaan Tuhan. Hal ini juga menunjukan pembenaran apabila mereka tidak bisa bersatu lagi, misalnya sang pria mendapatkan kekasih baru lalu menikah di perantauan, atau karena terlalu lama ditinggal, sang wanita dinikahi oleh orang lain sehingga tidak mungkin mereka berkumpul lagi, termasuk hilangnya kesempatan bermesraan di saat pesta perkawinan. Mereka masing-masing menikah dengan orang yang sendiri-sendiri dengan orang yang berbeda. Atau karena satu dan lain hal, misalnya sang pria meninggal dunia di perantauan, dan mungkin juga sang wanita meninggal dunia karena terlalu lama bersedih ditinggal kekasih. Itu semua bisa dibenarkan dengan alasan takdir Tuhan.

Dengan demikian tujuan komunikatif lirik lagu Malam Terakhir karya dan sekali gus dinyanyikan oleh Rhoma Irama bersama penyanyi wanita sebagai pasangannya adalah:

1) Memberitahukan atau memberikan narasi melalui lagu syahdu berirama melayu kepada pendengar tentang suatu keadaan malam hari saat-saat perpisahan dua remaja. Kekasih pria akan meninggalkan kekasih wanita untuk suatu tugas tertentu;

2) Meskipun terdengar syahdu, kedua kekasih itu tetap tidak melakukan perbuatan yang terlarang agama. Hal ini dibuktikan dengan pernyataan mereka tentang bermesraan di malam perkawinan mereka setelah mereka kembali berkumpul dan bukan pada malam terakhir saat mereka hendak berpisah.

3) Melalui narasi lirik lagu, Rhoma Irama juga memberikan pesan religi bahwa Takdir Tuhan adalah segalanya. Apapun rencana manusia, akan menjadi siasia manakala Tuhan menentukan takdir yang lain. Mereka berdua merencanakan kesetiaan. Sang wanita sabar dalam menanti kehadiran kekasihnya. Mereka memimpikan kemesraan di malam pesta perkawinan. Namun semua bisa hilang ketika Tuhan menentukan lain.

Untuk lirik lagu Satukan Hati Kami karya Pance Pondaag dapat dinarasikan sebagai berikut. Dimulai dengan Bait pertama: 


\section{Di sini setahun yang lalu \\ Menyatu hatiku dan hatimu \\ Tanpa janji-janji tanpa kemesraan \\ Kau diam aku pun membisu}

Baris pertama yang berbunyi Di sini setahun yang lalu dengan jelas menunjukkan Pance Pondaag akan bercerita tentang peristiwa yang terjadi setahun yang lalu. Ada apa setahun yang lalu antara Pance dan kekasihnya. Mereka sudah menjalin hubungan asmara. Tidak terlihat apakan dalam cerita tersebut kedua insan itu sudah atau belum resmi menikah.

Ternyata diantara mereka tidak ada terucap janji-janji layaknya sepasang kekasih.Dengan demikian sulit untuk menyimpulkan status keduanya (menikah atau belum).Akan tetapi, dari baris kedua ada tertulis Menyatu hatimu dan hatiku yang dapat dijadikan petunjuk bahwa mereka baru saja memadu kasih dan tentunya mereka belum menikah. Terlihat mereka sangat menjaga nilai-nilai kesopanan, yang didukung oleh bait yang tertulis: Tanpa kemesraan, dengan demikian dapat disimpulkan mereka hanyaduduk-duduk. Ditambah baris berikutnya "Kau diam, aku pun membisu."

Namun dapat juga disimpukan meraka justru sepasang suami istri.Argumennya adalah bahwa biasanya suami istri tidak dapat berbuat banyak menghadapi kenyataan.Hal ini ditunjukkan adanya tanpa kemesraan dan saling membisu.Situasinya begitu dramatis. Kemungkinan besar suami atau istri mendapat tugas dari kantor untuk kepentingan dinas, atau mendapat tugas studi lanjut jika masal bekerja sebagai dosen. Melepas suami atau untuk tugas negara (Misalnya menjadi tentara), juga tidak lah mudah.Resiko kematian dan tidak dapat berjumpa lagi bisa dikatakan relative tinggi.

Pertanyaan yang muncul adalah mengapa mereka saling membisu tanpa katakata.Betapa sulitnya mereka mengungkapkan perasaan. Mereka tidak tahu harus berkata dan berbuat apa, menghadapi peristiwa yang melanda keduanya. Peristiwa bersejarah itu terjawab pada baris pertama bait kedua, Kau pergi dengan cita-cita, yang diikuti Ke kota yang jauh di sana. Dengan demikian asumsi bahwa mereka suami istri makin mendekati kebenaran. Di sini sang suami atau istri (tergantung penyanyinya wanita atau laki-laki) pergi untuk melaksanakan tugas di kota yang jauh. Pada waktu lirik lagu ini populair, belum ada sarana komunikasi digital seperti sekarang ini. Telopon masih jarang, surat pun bisa memakan waktu 4 hingga 7 hari untuk bisa sampai, sekedar bertanya 'Hi, apa kabar?" Kirim telegram pun sedapat mungkin dihindari, sebab telegram pada waktu itu cenderung berkonotasi negative, yakni berita duka (kematian) atau kecelakaan.

Bait lengkapnya sebagai berikut:
Kau pergi dengan cita-cita
Ke kota yang jauh di sana
Pasrah sudah hati, hanya do'a restu
Kutunggu dengan sabar hati.

Baris ketiga "Pasrah sudah hati" mengandung makna religious (dalam bentuk kepasrahan) yakni sebagai hamba Tuhan yang beriman dan takwa, tidak ada pilihan lainkecuali pasrah pada kehendakNya. Istri atau suami harus merelakan kepergian belahan jiwa demi tugas negara (kantor). Ditambah dengan frasa "hanya do'a restu" rasanya semakin menambah nilai religiusitas lirik lagu tersebut. Bait ini ditutup dengan 
"Kutunggu dengan sabar hati." Baris yang sangat menyentuh yakni kesabaran dalam menunggu suami atau istri hingga pulang kembali ke pelukan setelah selesai tugas.

Lirik lagu ini diakhiri dengan bait yang amat religious sebagai berikut:

Siang malam hanya do'a yang ku panjatkan

Tuhan lingdungilah dia yang ku sayangi

Satukanlah hati kami berdua

Selamanya, selamanya

Baris pertama bait terakhir "Siang malam hanya do'a yang kupanjatkan." mengandung makna yang dalam. Bagaimana seorang istri atau suami mendoakan belahan jiwanya siang dan malam. Kalau yang beragama Islam barangkali setiap habis sholat fardu, dia berdoa untuk keselamatan suaminya, seperti terungkap pada baris berikutnya "Tuhan lindungilah dia yang kusayangi."Dengan satu permintaan, "Satukanlah hati kami berdua," sehingga tidak ada kata perpisahan kecuai maut yang merenggut salah satu atau keduanya. Bait diakhiri dengan baris "Selamanya-selamanya" jadi bukan sehari dua hari, sebulan dua bulan, setahun dua tahun tapi selamanya.

Bait terakhir ini mengandung makna berlapis (multiple meaning). Sebuah perilaku yang sangat religious, yakni siang malam selalu berdo'a agar Tuhan berkenan melindungi belahan jiwa tercinta, dengan satu permintaan, Satukanlah hati kami.Betapa tidak, di saat keduanya berjauhan, godaan akanmengincar dari hampir setiap sudut. Sepinya situasi malam hari yang normalnya diiringi dengan meningkatnya libido biologis, yang tak tersalurkan, akan menjadi sumber godaan yang sulit untuk dihindari jika tidak ada campur tangan Tuhan. Di siang hari, kemungkian besar bertemu kawan lain jenis dan berinteraksi baik formal maupun informal, akan menjadi sumber godaan. Dengan situasi yang sama-sama sendiri, maka tidak tertutup kemungkian akan terjadi perselingkuhan, yang bisa berkibat fatal bagi yang ditinggal di rumah.

Dari uraian di atas dapat disimpulkan bahwa tujuan komunikatif lirik lagu Satukan Hati Kami adalah menceritakan keadaan saat sang kekasih (suami / istri) hendak pergi menjalankan tugas. Saat itu begitu syahdu hingga kedua insan tak mampu berbuat apa-apa, juga tidak banyak berkata apapun. Namun dalam hati begitu rela melepas kekasih pergi dengan diiringi do'a baik siang maupun malam demi keselamatan sang kekasih.

Tuhan pun dimohon menyatukan hati ke dua insan, agar tidak terjadi hal-hal yang tidak diinginkan (perelingkuhan di rantau, misalnya).Audiens diharapkan menaruh empati pada cerita tersebut sehingga dapat menempatkan diri sebagai yang ditinggal atau yang meninggalkan. Apabila lagu dinyanyikan oleh laki-laki, maka pendengar lakilaki akan merasakan bagaimana ditinggal istri yang hendak tugas negara. Demikian juga, apabila lagu dinyanyikan oleh penyanyi wanita, maka pendengar wanita bisa hanyut seolah-olah dialah yang ditinggal suami pergi dalam tugas negara.

Dalam sebuah cerita, strutur generik dapat dikatakan sebagai langkah demi langkah bagaimana sang penulis cerita membangun cerita agar Nampak menarik. Demikian juga dengan lirik lagu.Ada bait pembuka, ada bait pokok dan ada pula bait penutup. Lirik lagu "Malam Terakhir" karya sekaligus dinyanyikan oleh Rhoma Irama memiliki sturktur generik seperti yang diuraikan dalam Tabel 4.1 Struktur Generik Malam Terakhir. 
Tabel 4.1 Struktur Generik Malam Terakhir

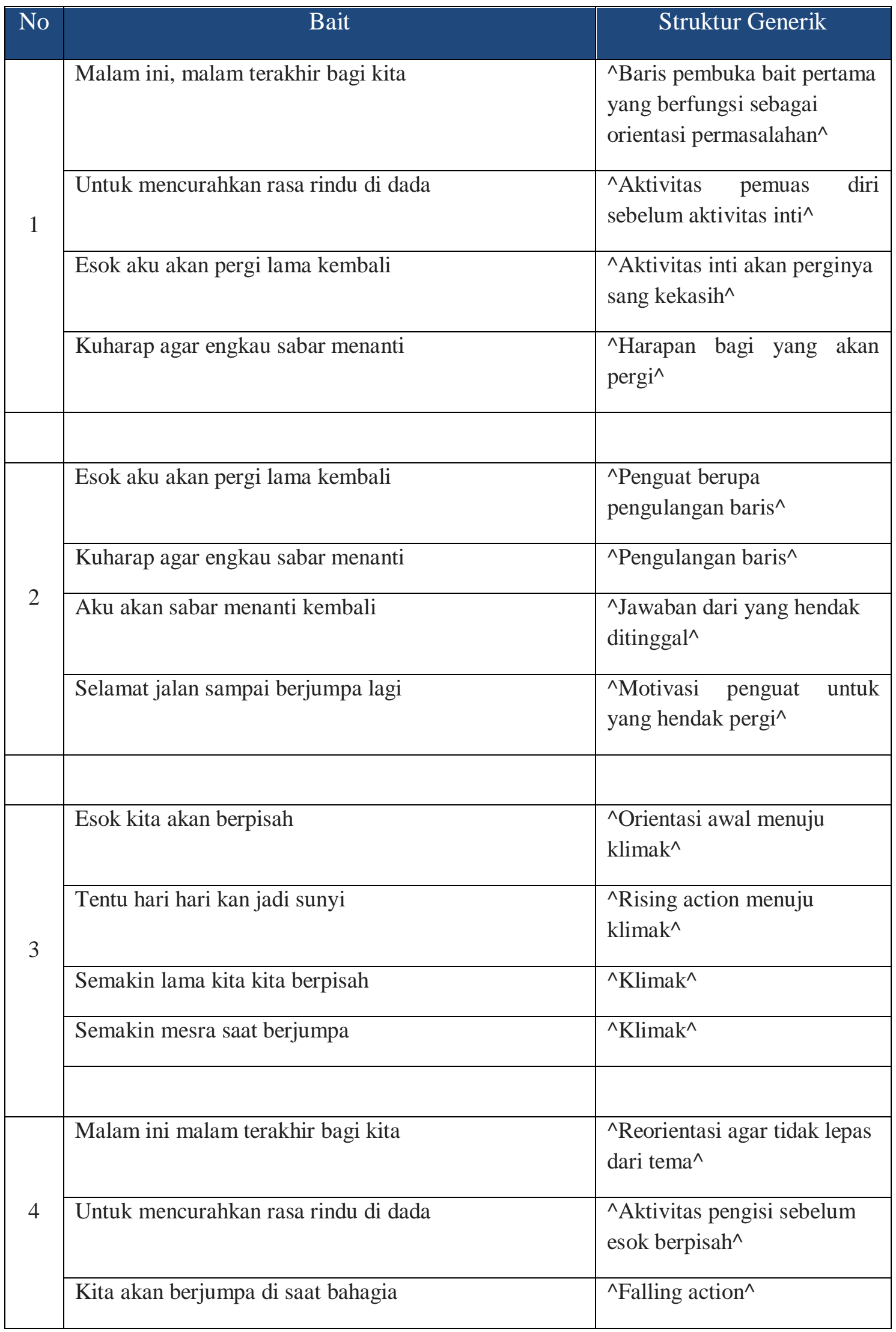




\begin{tabular}{|c|c|c|}
\hline & Di saat pesta perkawinan kita & $\begin{array}{l}\wedge \text { Membuka fakta bahwa } \\
\text { keduanya belum menikah^}\end{array}$ \\
\hline & Mengapa, mengapa hatiku berdebar-debar & ${ }^{\wedge}$ Rising action ${ }^{\wedge}$ \\
\hline & Seakan-akanku ragu merelakan keperginmu, kasih & ${ }^{\wedge}$ Kecurigaan wanita^ \\
\hline & Mengapa, mengapa hatiku berkata-kata & ${ }^{\wedge}$ Rising action \\
\hline & Seakan-akan berbisik bahwa kita tidak berjumpa lagi & ${ }^{\wedge}$ kekawatiran wanita $^{\wedge}$ \\
\hline \multirow[t]{5}{*}{6} & Kepergianku hanya untuk kembali & $\wedge^{\wedge} \mathrm{Jawaban}^{\wedge}$ \\
\hline & Kita berpisah untuk berjumpa lagi & ${ }^{\wedge}$ Meyakinkan^ \\
\hline & Kecuali bila Tuhan menghendaki & $\wedge^{\wedge}$ Religi^ \\
\hline & Tentu kita haru rela hati & ${ }^{\wedge}$ Religi^ \\
\hline & Karena kehendakNya, itu yang terjadi & ${ }^{\wedge}$ Religi^ \\
\hline
\end{tabular}

Dari struktur generik di atas, terlihat bahwa Rhoma Irama terjebak dalam bersikap.Awalnya lagu "Malam Terakhir" terkesan sangat menyentuh dan romantis bahkan dapat dikatakan begitu syahdu. Dapat dibayangkan apa yang dilakukan bila ada dua sejoli yang hanya memiliki waktu "malam ini" untuk bersuka cita menumpahkan rindu (lihat : Bait $1 \mathrm{~s} / \mathrm{d} 4$ baris ke 2). Namun, perlu diingat bahwa Rhoma Irama, sejak pulang ibadah haji yang pertama dan mengganti namanya menjadi Rhoma Irama (semula Oma Irama), beliau fokus pada lagu lagu berirama ndangdut tapi bernuansa Islami.

Oleh karena itu, kemesraan dan romantisme yang dibangun dalam lagu Malam Terakhir dipatahkan dengan bait ke 4 , baris ke 4 (Di saat pesta perkawinan kita).Kalimat ini mampu menghancurkan khayalan audiens tentang adegan yang dilakukan oleh kedua insan berlawanan jenis di saat-saat yang demikian.Mereka ternyata sanggup untuk menahan gejolak libido hingga saat perkawinan mereka.

Untuk lebih bernuansa religi, Rhoma menciptakan rising action baru yang sebenarnya terlalu exaggerated menurut teori sastra. Diciptakanlah situasi bahwa si wanita ragu untuk melepas kepergian kekasih (Bait 5).Meskipun Rhoma kembali menegaskan bahwa kepergiannya untuk kembali, namun semuanya diserahkan pada takdir Tuhan.

Bila diteliti lebih dalam, sebanarnya bait-bait terakhir (kepasrahan pada Tuhan) dapat menjadi pembenaran bahwa seandainya mereka tidak berkumpul kembali, itu semua kehendak yang Mahakuasa. Ada sisi negative nya pada bagian ini, yakni seandainya di rantau kelak sang kekasih menemukan wanita lain yang dirasa lebih baik, dan kemudian terjadi jalinan kasih baru, maka hal ini mendapat justifikasi sebagai takdir Tuhan. Hal yang demikian sangat mungkin karena wanita yang ditinggal belum ada ikatan perkawinan. 
Untuk lirik lagu 'Satukan Hati Kami' karya Pance Pondaag, analisis struktur generiknya dapat diuraikan sebagai berikut.

Tabel 4.2 Struktur Generik Lirik Lagu 'Satukan Hati Kami'

\begin{tabular}{|c|c|c|}
\hline No & Bait & Struktur Generik \\
\hline \multirow{4}{*}{1} & Di sini setahun yang lalu & $\begin{array}{l}\wedge \text { Marka diskursus bahwa lagu ini } \\
\text { akan mengisahkan sesuatu } \\
\text { melalui 'flashback' (kilas balik)^ }\end{array}$ \\
\hline & Menyatu hatiku dan hatimu & $\begin{array}{l}{ }^{\wedge} \text { Rising action adanya dua hati } \\
\text { yang telah bersatu, bisa sebagai } \\
\text { kekasih atau suami istri^ }\end{array}$ \\
\hline & Tanpa janji-janji, tanpa kemesraan & ${ }^{\wedge}$ Atribut menyatunya hati^ ${ }^{\wedge}$ \\
\hline & Kau diam aku pun membisu & $\wedge^{\wedge}$ Atribut menyatunya hati^ ${ }^{\wedge}$ \\
\hline & Kau pergi dengan cita-cita & $\begin{array}{lcc}\wedge \text { Respon mengapa } & \text { tanpa } \\
\text { kemesraan dan membisu^ } & \end{array}$ \\
\hline 2 & Ke kota yang jauh di sana & $\wedge$ Atribut respon^ \\
\hline & Pasrah sudah hati, hanya do'a restu & $\wedge^{\wedge}$ Atribut religi^ \\
\hline & Kutunggu dengan sabar hati & ${ }^{\wedge}$ Konsekwensi kepasrahan^ ${ }^{\wedge}$ \\
\hline \multirow{4}{*}{3} & Siang malam hanya do'a yang kupanjatkan & $\begin{array}{l}\text { ^Klimak kepasrahan pada } \\
\text { Tuhan^ }\end{array}$ \\
\hline & Tuhan lindungilah dia yang kusayangi & ${ }^{\wedge}$ Konten do’a^ \\
\hline & Satukanlah hati kami berdua & ${ }^{\wedge}$ Atribut konten do’a^ \\
\hline & Selamanya, selamanaya & ${ }^{\wedge}$ Atribut konten do' $\mathrm{a}^{\wedge}$ \\
\hline
\end{tabular}

Dari struktur generik, terlihat Pance Pondaag mencipta lirik lagu dengan sederhana (Hanya 3 bait). Bait ke tiga diulang-ulang sebagai refrained-nya. Namun demikian, lagunya mampu membentuk diskursus yang lengkap.

Seorang wanita/pria (tergantung yang membawakan lagunya), saat menanti kepulangan pasanganya, berkisah kilas balik tentang peritiwa setahun yang lalu, saat kekasih hendak pergi untuk suatu tugas ke kota yang jauh. Begitu religiusnya Pance mampu mengolah bait dan kata sehingga terkesan adanya kepasrahan dan do'a atas keselamantan bagi yang akan menjalankan tugas. Ada satu permintaan dalam do'a harian yang dilantunkan yang ada di rumah, yakni memohon agar Tuhan menyatukan hati mereka, ditambah dengan atribut 'selamanya, selamanya'. 
Do'a semacam ini (satukan hati) dapat menjadi benteng pasangan suami istri dari perselingkuhan atau bencana lain yang berakibat retaknya tali perkawinan atau 'perpacaran'. Pance Pondaag mampu mengemas dalam lagu yang sangat relevan dan mengena.

\subsubsection{Perbandingan Fitur Linguisik}

Berikut menunjukkan perbandingan lirik lagu "Malam Terakir" dan "Satukan Hati Kami” dari segi fitur linguistis.

Tabel 4.3 Fitur Linguistik

\begin{tabular}{cccc}
\hline No & Fitur Linguistik & Rhoma & Pance \\
\hline $\mathbf{1}$ & Temporer & $\sqrt{ }$ & \\
$\mathbf{2}$ & Flashback & & $\sqrt{ }$ \\
$\mathbf{3}$ & Orientasi & $\sqrt{ }$ & $\sqrt{ }$ \\
$\mathbf{4}$ & Rising action & $\sqrt{ }$ & $\sqrt{ }$ \\
$\mathbf{5}$ & Klimaks & $\sqrt{ }$ & \\
$\mathbf{6}$ & Falling action & $\sqrt{ }$ & \\
$\mathbf{7}$ & Exaggeration & $\sqrt{ }$ & $\sqrt{ }$ \\
$\mathbf{8}$ & Ekspresi harapan & $\sqrt{ }$ & $\sqrt{ }$ \\
$\mathbf{9}$ & Religiusitas & $\sqrt{ }$ & $\sqrt{ }$ \\
$\mathbf{1 0}$ & Romantisme & & \\
\hline
\end{tabular}

Tabel 4.3 menunjukkan perbedaan yang mencolok antara Rhoma Irama dengan Pance Pondaag yakni saat terjadinya peristiwa.Rhoma menggunakan metode temporer dalam membangun kisahnya melalui lagu.Hal ini dapat dilihat dari penggunaan kata Malam ini, dan Esok ... yang menunjukkan saat kejadian yang temporer.Sedangkan Pance menggunakan metode kilas balik atau flashback. Hal ini dapat dilihat dari penggunaan frasa $\mathrm{Di}$ sini setahun yang lalu yang menunjukkan bahwa pebahasa hendak melakukan kilas balik peristiwa yang dialami.

Berikutnya adalah falling action dan exaggeration yang dipakai Rhoma namun tidak digunakan oleh Pance. Rhoma menggunakan falling action bahwa kemesraan yang sebenarnya akan terjadi saat malam pesta pernikahan (bukan saat malam mau ditinggal pergi). Ini disebabkan karena belum menikah. Exaggeration yang dipakai Rhoma adalah berupa penyimpangan alur lagu, yakni keraguan pihak wanita apakah akan dapat berkumpul lagi. Tujuan exaggeration ini adalah untuk menepis segala tuduhan negative terhadap Rhoma Irama yang sudah fokus pada irama ndangdut bernuansa islami.Sedangakan Pance tidak menggunakan falling action karena lagunya bersifat abadi, dilihat dari reff yang berulang-ulang.

Terkait dengan religiusitas dan romantisme, berikut ini akan disajikan hasil survei terhadap 20 mahasiswa program studi sastra Inggris, FBIB Unisbank dalam tabel berikut.

Tabel 4.4 Religiusitas dan Romantisme Versi Mahasiswa

\begin{tabular}{llccc}
\hline No & \multicolumn{1}{c}{ Indikator } & Bait & Rhoma (\%) & Pance (\%) \\
\hline $\mathbf{1}$ & Sangat romantic & 1 & 25 & 80 \\
$\mathbf{2}$ & Romantis & & 75 & 20 \\
$\mathbf{3}$ & Neutral & & & \\
$\mathbf{4}$ & Religious & & & \\
$\mathbf{5}$ & Sangat religious & & \\
\hline
\end{tabular}




\begin{tabular}{|c|c|c|c|}
\hline Sangat romantic & 2 & 20 & \\
\hline Romantis & & 80 & \\
\hline Neutral & & & \\
\hline Religious & & & 85 \\
\hline Sangat religious & & & 15 \\
\hline Sangat romantic & 3 & 5 & \\
\hline Romantis & & 95 & \\
\hline Neutral & & & \\
\hline Religious & & & \\
\hline Sangat religious & & & 100 \\
\hline Sangat romantic & 4 & 35 & - \\
\hline Romantis & & 65 & - \\
\hline Neutral & & & - \\
\hline Religious & & & - \\
\hline Sangat religious & & & - \\
\hline Sangat romantic & 5 & & \\
\hline Romantis & & & \\
\hline Neutral & & & \\
\hline Religious & & 75 & \\
\hline Sangat religious & & 15 & \\
\hline
\end{tabular}

Dari Tabel 4.4, dapat diketahui bahwa bait pertama baik Rhoma maupun Pance sama-sama memulai dengan romantisme. Sebanyak 25\% mahasiswa setuju bahwa bait pertama dapat digolongkan sebagai 'sangat romantis'. Sisanya $(75 \%)$ menyatakan 'romantis' untuk bait pertama "Malam Terakhir'.Sedangakan untuk lirik lagu karya Pance, $80 \%$ mahasiswa mengatakan 'sangat romantis'.Sisanya (20\%) mengatakan 'romantis' untuk lirik lagu "Satukan Hati Kami”.

Bait ke 2 lirik lagu karya Pance sudah mulai dengan nilai religiusitas, terlihat dari baris "Pasrah sudah hati, hanya do'a restu." dan "Kutunggu dengan sabar hati". Sedangkan Rhoma Irama pada bait ke 2 masih kenthal dengan romantisme, terlihat dari baris "Aku akan sabar menanti kau kembali." dan"Selamat jalan dan sampai jumpa lagi."

Bait ke 3 lirik lagu "Satukan Hati Kami" semakin menunjukkan religiusitas yang tinggi (100\%), terlihat dari baris Siang malam hanya do'a yang kupanjatkan, Tuhan lindungilah dia yang kusayangi, Satukanlah hati kami berdua, danSelamanya, selamanya.Semenara itu Rhoma Irama menampilkan nilai religiusitas dalam bentuk exaggeration, untuk menjawab konsekwensi dirinya sebagai juru dahwah.Dengan demikian, terjawab sudah bahwa lirik lagu Satukan Hati Kami karya Pance Pondaag lebih bernuansa relegi dibanding lirik lagu "Malam Terakhir" karya Rhoma Irama meskipun keduanya diawali dengan nuansa romantisme.

Temuan di atas dapat dijadikan titik awal pembangunan karakter para remaja melalui pengajaran (pengkajian) karya sastra dalam implikasi pedagogis.Setiap karya sastra baik itu berupa puisi, lirik lagu, atau novel pasti mengandung ajaran moral yang disisipkan oleh pengarangnya.Namun demikian, guru atau dosen harus dapat memilih karya sastra yang banyak mengandung nilai-nilai religious moralitas.Dunia maya dengan kebebasan penyebaran informasi melalui internet sangat kuat sekali dalam 
membentuk karakter anak bangsa. Meskipun ada semacam application control untuk membatasi akses anak terhadap pengaruh negatif dunia maya, anak-anak pun tidak kurang akal untuk menerobos saringan moral tersebut.

Terkait dengan perkembangan teknologi digital, dosen (guru) sastra tidak dapat lepas dari keharusan menguasai computer literacy. Ini sejalur dengan penelitian literasi era indutri 4.0(Fitriani \& Aziz, 2019) Banyak sekali karya-karya sastra (produk sastra) yang telah dikelola di dunia maya. Karya-karya sastra bahasa Inggris klasik sekelas Shakerspeare juga banyak di bahas di dunia maya. Perguruan tinggi terkemuka bahkan menggunakan media interaktif (e-learning) dalam pengajaran karya sastra. Hal ini merupakan angin segar bagi pendidikan sastra yang bagi pihak yang masih berkutat dengan paper-based literature education harus segera mengubah paradigma menjadi multi-media-based literature education di mana penggunaan internet untuk berbagai kegiatan pembelajaran sangat dianjurkan.

Kenakalan remaja yang dipicu oleh bebasnya akses dunia maya disinyalir disebabkan karena keringnya sentuhan sastra di hati mereka. Ini merupakan tantangan berat bagi pendidikan sastra untuk berkontribusi menyelamatkan anak bangsa. Kiranya perlu dikembangkan pengajaran karya sastra bagi mahasiswa yang bersifat multidisipliner agar supaya semua mahasiswa dari disiplin ilmu apapun dapat tersentuh dengan nilai-nilai religious moralitas.

Terakhir, namun tidak kalah pentingnya dalam penelitian ini adalah digunakan ancangan linguistis (semiotika) dalam menganalisis karya sastra yang bentuknya lirik lagu (Asriningsari \& Umaya, 2010). Perkembangan terakhir teori linguistik adalah gencarnya para linguist merambah ke karya sastra sebagai obyek penelitian melalui kerangka analisis linguistik, khususnya yang bergelut dengan semiotika, analisis wacana dan analisis wacana kritis, yang oleh pakar sastra dianggap relatif sama dengan stilistik.

\section{KESIMPULAN}

Tujuan komunikatif lirik lagu Malam Terakhir adalah untuk memberikan informasi tentang event tertentu yang sifatnya temporal, yakni sebuah kejadian yang dialami pada saat lagu dinyanyikan (duet penyanyi sebagai pelaku peristiwa).Ada janji dan harapan namun semua tergantung kuasa Tuhan.Sedangakan Satukan Hati Kami memiliki tujuan komunikatif untuk memberikan kilas balik (flashback), pada suatu peristiwa masa lalu seperti justifiksi dalam baris Di sini setahun yang lalu.

Terkait dengan struktur generik, Pance Pondaag lebih terkesan sederhana dan mudah ditebak serta mengandung nilai kepasrahan dan religiusitas yang tinggi. Di lain pihak, Rhoma Irama menampilkan Exaggeration agar pada akhir lirik lagu ada nuansa religi sekaligus menepis dugaan-dugaan negative pada peristiwa malam terakhir.

Oleh karena itu dapat disimpulkan bahwa lirik lagu Satukan Hati Kami karya Pance Pondaag lebih alami dan memiliki nuansa atau nilai-nilai religiusitas yang lebih tinggi dibanding lirik lagu Malam Terakhir yang terkesan justru lebih menonjolkan nilai romantisme. Kalaupun ada sentuhan religi, itu sifatnya Exaggeration (mengada-ada) sebagai konsekwensi pribadi Rhoma Irama selaku figur publikyang religius. Sejak kepulangan ibadah haji, nama Oma Irama diganti menjadi Rhoma Irama dan kemudian fokus pada lagu-lagu ruhani bernuansa nilai-nilai Islami.

Nilai-nilai romantisme dan religiusitas didukung oleh survei terhadap 20 mahasiswa program studi sastra Inggris, disertai bukti-bukti linguistis agar temuan 
dapat tervalidasi, kredible dan riliabel bahwa kedua lirik lagu tersebut memiliki nuansa romantisme dan religiusitas dengan proporsi dan tujuan yang berbeda.

Implikasi pedagogis yang dapat ditarik dari penelitian ini adalah bahwa untuk membangun karakter remaja, karya sastra bisa menjadi pilihan untuk diajarkan dalam dimensi multi-disipliner agar supaya generasi anak bangsa dari berbagai disiplin ilmu mendapat sentuhan nilai sastra.Disamping itu, penelitian ini menggunakan ancangan linguistis (kajian wacana) dalam menganalisis lirik lagu.

Rekomendasi yang dapat ditawarkan adalah pertama langkah konkret rekonstruksi mata kuliah sastra dengan menggunakan karya-karya sastra sebagai bahan kajian yang memungkinkan dapat berkontribusi untuk membangun karakter anak bangsa (mahasiswa). Kedua, pengajaran karya sastra dengan menggunakan multimedia dan cyber learning yang tentunya memerlukan update ketrampilan computer literacy bagi dosen dan mahasiswa.Terakhir, perlu dibakukan ancangan linguistis (analisis semiotika dan wacana) untuk menganalisis karya sastra dari segi tujuan komunikatif, struktur generik dan fitur linguistis.

\section{UCAPAN TERIMA KASIH}

Tim peneliti mengucapkan banyak terima kasih kepada LPPM (Lembaga Penelitian dan Pengabdian kepada Masyarakat) Universitas Stikubank (UNISBANK) Semarang yang telah menjadi sponsor dalam penelitian ini.

\section{REFERENSI}

Alviani, E. S. (2012). Bentuk Pertunjukan Orkes Dangdut Parodi Senggol Tromol di Semarang: Kajian Bentuk dan Fungsi. Harmonia: Journal Of Arts Research And Education, 12(1).

Askehave, I., \& Swales, J. M. (2001). Genre identification and communicative purpose: A problem and a possible solution. Applied Linguistics, 22(2), 195-212.

Asriningsari, A., \& Umaya, N. (2010). Semiotika Teori dan Aplikasi pada Karya Sastra. UPGRIS PRESS.

Bhatia, V. K. (1999). Integrating products, processes, purposes and participants in professional writing. Writing: Texts, Processes and Practices, 21-39.

Falah, A. M. (2019). METAFORA PADA LAGU ARCTIC MONKEYS DALAM ALBUM AM. Universitas Muhammadiyah Sukabumi.

Fitriani, Y., \& Aziz, I. A. (2019). LITERASI ERA REVOLUSI INDUSTRI 4.0. In Prosiding Seminar Nasional Bahasa dan Sastra Indonesia (SENASBASA) (Vol. 1).

Halliday, M. A. K., Matthiessen, C., \& Halliday, M. (2014). An introduction to functional grammar. Routledge. 
Hamdi, M., \& Ismaryati, S. (2014). Metodologi Penelitian Administrasi.

Herlin, W. (2015). Melody cinta. Universitaire Bibliotheek Leiden.

Islami, S. H. (2016). Pesan Dakwah dalam Lirik Lagu Ebiet G. Ade. Tabligh: Jurnal Komunikasi Dan Penyiaran Islam, 1(1), 105-128.

Khodijah, S. (2018). Pembelajaran Nasionalisme Melalui lagu-lagu Rhoma Irama. Proceeding of The URECOL, 259-266.

Kizer, E. J. (1983). Protest song lyrics as rhetoric. Popular Music \& Society, 9(1), 3-11.

Mintargo, W., Soedarsono, R. M., \& Ganap, V. (2014). Fungsi lagu perjuangan sebagai pendidikan karakter bangsa. Jurnal Kawistara, 4(3).

Rokhmansyah, A. (2014). Studi dan Pengkajian Sastra: perkenalan awal terhadap ilmu sastra. Graha Ilmu.

Romadhon, A. (2013). Musik Dangdut Koplo di Grup Bhaladika Semarang dalam Konteks Perubahan Sosial Budaya. Catharsis, 2(1).

Saksono, S. T. (2009). LINGUISTIC CRITICISM AS A FIRST PHASE TO LITERARY CRITICISM. Prosodi, 3(1).

Sari, P. P. (n.d.). Nilai-Nilai Moral dalam Lirik Lagu Daerah Kerinci Karya H. Atmajar Idris. Jurnal Nilai-Nilai Moral Dalam Lirik Lagu Daerah Kerinci Karya H. Atmajar Idris.

Sitowati, I. (2010). Relevansi Selera Musik dan Kelas Sosial.

Suhita, S \& Purwahida, R. (2018). Apresiasi Sastra Indonesia. Bandung: Remaja Rosdakarya.

UMAM, K. (2016). MUSIK DANGDUT RHOMA IRAMA SEBAGAI MEDIA KRITIK POLITIK PADA ORDE BARU TAHUN 1977-1983. Avatara, 4(3).

Umaya, Y. F. (2018). Nilai-nilai Tauhid dalam syair lagu karya Rhoma Irama. Universitas Islam Negeri Maulana Malik Ibrahim.

Veronika, A. V. (2016). Pesan Dakwah Dalam Syair Lagu Cari Berkah Album 3 In 1 Grup Musik Wali Band. IAIN Purwokerto.

Wardoyo, S. (2009). Semiotic Reading Positions and Intertextuality. In Proceeddings: 2nd Rafil International Conference (Versi asli/terjemahan).

Wiratno, T. (2016). Pengembangan Kurikulum dan Materi Ajar Berbasis Linguistik Sistemik Fungsional. Seminar Nasional Kajian Bahasa, Sastra, dan Pengajarannya (SEMNAS KBSP) IV 2016. 
Yunus, A. A. (2018). Pesan dakwah Band Metal Burgerkill dalam lagu Tiga Titik Hitam: analisis wacana. UIN Sunan Ampel Surabaya.

Zolkifli, N. H., Bakar, A., \& Saniah, S. (2011). Unsur eufemisme dalam novel Papa dan Azfa Hanani. Jurnal Bahasa DBP. 